\title{
On Opial's type inequalities for an integral operator with homogeneous kernel
}

\author{
Chang-Jian Zhao ${ }^{1 *}$ and Wing-Sum Cheung ${ }^{2}$
}

* Correspondence: chjzhao@163. com

'Department of Mathematics, China Jiliang University, Hangzhou 310018, China

Full list of author information is available at the end of the article

\section{Abstract}

In this article, we establish some new Opial's type integral inequalities for an integral operator with homogeneous kernel. The results in special cases yield some of the interrelated results and provide new estimates on inequalities of this type.

MS (2000) Subject Classification: 26D15.

Keywords: Opial's inequality, Hölder's inequality, Jensen's inequality, integral operator, homogeneous kernel

\section{Introduction}

In 1960, Opial [1] established the following inequality:

Theorem 1.1 Suppose $f \in C^{1}[0, h]$ satisfies $f(0)=f(h)=0$ and $f(x)>0$ for all $x \in(0, h)$. Then

$$
\int_{0}^{h}\left|f(x) f^{\prime}(x)\right| d x \leq \frac{h}{4} \int_{0}^{h}\left(f^{\prime}(x)\right)^{2} d x .
$$

The Opial's type inequality was first established by Willett [2]:

Theorem 1.2 Let $x(t)$ be absolutely continuous in $[0, a]$, and $x(0)=0$. Then

$$
\int_{0}^{a}\left|x(t) x^{\prime}(t)\right| d t \leq \frac{a}{2} \int_{0}^{a}\left|x^{\prime}(t)\right|^{2} d t
$$

A non-trivial generalization of Theorem 1.2 was established by Hua [3]:

Theorem 1.3 Let $x(t)$ be absolutely continuous in $[0, a]$, and $x(0)=0$. Further, let $l$ be a positive integer. Then

$$
\int_{0}^{a}\left|x(t) x^{\prime}(t)\right| d t \leq \frac{a^{l}}{l+1} \int_{0}^{a}\left|x^{\prime}(t)\right|^{l+1} d t .
$$

A sharper inequality was established by Godunova [4]:

Theorem 1.4 Let $f(t)$ be convex and increasing functions on $[0, \infty)$ with $f(0)=0$. Further, let $x(t)$ be absolutely continuous on $[\alpha, \tau]$, and $x(\alpha)=0$. Then, following inequality holds

$$
\int_{\alpha}^{\tau} f^{\prime}(|x(t)|)\left|x^{\prime}(t)\right| d t \leq f\left(\int_{\alpha}^{\tau}\left|x^{\prime}(t)\right| d t\right) .
$$


Opial's inequality and its generalizations, extensions, and discretizations play an important role in establishing the existence and uniqueness of initial and boundary value problems for ordinary and partial differential equations as well as difference equations [5-13]. For Opial-type integral inequalities involving high-order partial derivatives, we refer the readers to see $[14,15]$. For an extensive survey on these inequalities, see [16]. Mitrinović and Pečarić [17] proved some new extensions of Opial's type inequalities. The aim of this article is to establish some Opial-type inequalities, which are some extensions of Godunova and Levin's, Mitrnović and Pečarić inequalities.

\section{Statement of results}

Here, we shall extend some of the previous results for the singular integral operator $T$ which have an integral representation. For this, we say that the integral operator $T$ (f)y belongs to the class $U(f, K)$ if it can be represented in the following form

$$
T(f) y=\int_{0}^{+\infty} K(y, x) f(x) d x, x \in[0,+\infty),
$$

where $f(x)$ is a continuous function on $[0,+\infty)$, and $K(y, x)$ is a non-negative homogeneous kernel function defined on $[0,+\infty) \times[0,+\infty)$, such that $T(f) y>0$ if $f(x)>0$, where $x \in[0,+\infty)$.

Theorem 2.1 For $i=1,2,3$, let $T\left(f_{i}\right) y \in U\left(f_{i}, K\right)$, where $f_{2}(x)>0, x \in[0,+\infty)$. Further, let $p(x)>0, x \in[0,+\infty)$, and let $g(y, x)$ be convex and increasing on $[0, \infty) \times$ $[0, \infty)$. Then the following inequality holds

$$
\int_{0}^{+\infty} p(y) g\left(\left|\frac{T\left(f_{1}\right) y}{T\left(f_{2}\right) y}\right|,\left|\frac{T\left(f_{3}\right) y}{T\left(f_{2}\right) y}\right|\right) d y \leq \int_{0}^{+\infty} \phi(y) g\left(\left|\frac{f_{1}(y)}{f_{2}(y)}\right|,\left|\frac{f_{3}(y)}{f_{2}(y)}\right|\right) d y,
$$

where

$$
\phi(\gamma)=f_{2}(y) \int_{0}^{+\infty} \frac{p(x) K(x, y)}{T\left(f_{2}\right) x} d x .
$$

Remark 2.2 Let the singular integral operator $T(f) y$ change to a function $x(t)$, so we say that the function $x(t)$ belongs to the class $\bar{U}(y, K)$ if it can be represented in the following form

$$
x(t)=\int_{\alpha}^{\tau} K(t, s) y(s) d s, t \in[\alpha, \tau],
$$

where $y(t)$ is a continuous function on $[\alpha, \tau]$, and $K(t, s)$ is a non-negative kernel defined on $[\alpha, \tau] \times[\alpha, \tau]$; such that $x(t)>0$ if $y(t)>0, t \in[\alpha, \tau]$. Taking these in Theorem 2.1 and with suitable modifications, then (2.2) becomes the following established by Mitrinović and Pečarić [17].

$$
\int_{\alpha}^{\tau} p(t) f\left(\left|\frac{x_{1}(t)}{x_{2}(t)}\right|,\left|\frac{x_{3}(t)}{x_{2}(t)}\right|\right) d t \leq \int_{\alpha}^{\tau} \phi(t) f\left(\left|\frac{y_{1}(t)}{y_{2}(t)}\right|,\left|\frac{y_{3}(t)}{y_{2}(t)}\right|\right) d t
$$

where

$$
\phi(t)=\gamma_{2}(t) \int_{\alpha}^{\tau} \frac{p(s) K(s, t)}{x_{2}(s)} d s .
$$


Remark 2.3 In particular, if $\lambda>0$ we have

$$
K(t, s)=K_{\lambda}(t, s)= \begin{cases}\frac{(t-s)^{\lambda-1}}{\Gamma(\lambda)}, & s \leq t \\ 0 & s>t .\end{cases}
$$

then $y(t)$ is the derivative of order $\lambda$ of $x(t)$ in the sense of Riemann-Liouville. Thus, if $x(t)$ is differentiable, then for $\lambda=1$, it follows that $y(t)=x^{\prime}(t)$.

Further, taking for $f(x, y)=f(x)$ and $K(t, s)=K_{\lambda}(t, s)$ in (2.3), (2.3) reduces to a result of Godunova and Levin [18].

Now, let $T(f) y \in U(f, K)$, where $K(y, x)=0$ for $x>y$. Such the singular integral operator we shall say belong to the class $U_{1}(f, K)$. It is clear that in the case, we have

$$
T(f) y=\int_{0}^{y} K(y, x) f(x) d x .
$$

Theorem 2.4 Let the function $f(x)$ be differentiable on $[0, \infty)$, and that for $v>1$ the function $f\left(x^{1 / v}\right)$ be convex and $f(0)=0$, and $\frac{1}{\mu}+\frac{1}{v}=1$. Further, let $T(f) y \in U_{1}(f, K)$, where

$$
\left(\int_{0}^{\gamma} K(y, x)^{\mu} f(x) d x\right)^{1 / \mu} \leq M
$$

Then

$$
\begin{aligned}
& \int_{0}^{+\infty}|T(f) y|^{(1-v)} f^{\prime}(|T(f) y|)|f(y)|^{v} d y \\
& \leq \frac{v}{M^{v}} f\left(M\left(\int_{0}^{+\infty}|f(y)|^{v} d y\right)^{1 / v}\right) .
\end{aligned}
$$

Remark 2.5 Let the singular integral operator $T(f) y$ change to a function $x(t)$, so we say that the function $x(t)$ belongs to the class $\bar{U}(y, K)$. Taking these in Theorem 2.4 and with suitable modifications, then (2.5) becomes the following result.

$$
\int_{\alpha}^{\tau}|x(t)|^{1-v} f^{\prime}(|x(t)|)|y(t)|^{v} d t \leq \frac{v}{M^{v}} f\left(M\left(\int_{\alpha}^{\tau}|y(t)|^{v} d t\right)^{1 / v}\right) .
$$

This is just a new result established by Mitrinović and Pečarić [17].

\section{Proofs of results}

Proof of Theorem 2.1 From the hypotheses of Theorem 2.1, it turn out that

$$
\begin{gathered}
\int_{0}^{+\infty} p(y) g\left(\left|\frac{T\left(f_{1}\right) y}{T\left(f_{2}\right) y}\right|,\left|\frac{T\left(f_{3}\right) y}{T\left(f_{2}\right) y}\right|\right) d y \\
=\int_{0}^{+\infty} p(y) g\left(\left|\frac{1}{T\left(f_{2}\right) y} \int_{0}^{+\infty} K(y, x) f_{2}(x) \frac{f_{1}(x)}{f_{2}(x)} d x\right|,\right. \\
\left.\leq \frac{1}{\left.T\left(f_{2}\right) y\right)} \int_{0}^{+\infty} K(y, x) f_{2}(x) \frac{f_{3}(x)}{f_{2}(x)} d x \mid\right) d y \\
\leq \int_{0}^{+\infty} p(y) g\left(\int_{0}^{+\infty} \frac{K(y, x) f_{2}(x)}{T\left(f_{2}\right) y}\left|\frac{f_{1}(x)}{f_{2}(x)}\right| d x,\right. \\
\left.\int_{0}^{+\infty} \frac{K(y, x) f_{2}(x)}{T\left(f_{2}\right) y}\left|\frac{f_{3}(x)}{f_{2}(x)}\right| d x\right) d y .
\end{gathered}
$$


By using the Jensen integral inequality, we have

$$
\begin{gathered}
\int_{0}^{+\infty} p(y) g\left(\left|\frac{T\left(f_{1}\right) y}{T\left(f_{2}\right) y}\right|,\left|\frac{T\left(f_{3}\right) y}{T\left(f_{2}\right) y}\right|\right) d y \\
\leq \int_{0}^{+\infty} p(y)\left(\int_{0}^{+\infty} \frac{K(y, x) f_{2}(x)}{T\left(f_{2}\right) y} g\left(\left|\frac{f_{1}(x)}{f_{2}(x)}\right|,\left|\frac{f_{3}(x)}{f_{2}(x)}\right|\right) d x\right) d y \\
=\int_{0}^{+\infty} g\left(\left|\frac{f_{1}(x)}{f_{2}(x)}\right|,\left|\frac{f_{3}(x)}{f_{2}(x)}\right|\right) f_{2}(x)\left(\int_{0}^{+\infty} \frac{p(y) K(y, x)}{T\left(f_{2}\right) y} d y\right) d x \\
=\int_{0}^{+\infty} \phi(x) g\left(\left|\frac{f_{1}(x)}{f_{2}(x)}\right|,\left|\frac{f_{3}(x)}{f_{2}(x)}\right|\right) d x
\end{gathered}
$$

where

$$
\phi(x)=f_{2}(x) \int_{0}^{+\infty} \frac{p(y) K(y, x)}{T\left(f_{2}\right) y} d y .
$$

Hence

$$
\int_{0}^{+\infty} p(y) g\left(\left|\frac{T\left(f_{1}\right) y}{T\left(f_{2}\right) y}\right|,\left|\frac{T\left(f_{3}\right) y}{T\left(f_{2}\right) y}\right|\right) d y \leq \int_{0}^{+\infty} \phi(y) g\left(\left|\frac{f_{1}(\gamma)}{f_{2}(y)}\right|,\left|\frac{f_{3}(y)}{f_{2}(y)}\right|\right) d y,
$$

where

$$
\phi(\gamma)=f_{2}(y) \int_{0}^{+\infty} \frac{p(x) K(x, y)}{T\left(f_{2}\right) x} d x .
$$

This completes the proof.

Proof of Theorem 2.4 From the hypotheses of Theorem 2.4 and in view of Hölder's inequality,

we obtain

$$
\begin{gathered}
|T(f) y| \leq \int_{0}^{y} K(y, x)|f(x)| d x . \\
\leq\left(\int_{0}^{y}(K(y, x))^{\mu} d x\right)^{1 / \mu}\left(\int_{0}^{y}|f(x)|^{v} d x\right)^{1 / v} \\
\leq M\left(\int_{0}^{y}|f(x)|^{v} d x\right)^{1 / v} .
\end{gathered}
$$

Now, let

$$
z(y)=\int_{0}^{y}|f(x)|^{v} d x
$$

Hence

$$
z^{\prime}(y)=|f(y)|^{\nu} .
$$

Moreover, notes that

$$
|T(f) y| \leq M(z(y))^{1 / v} .
$$

Further, from the convexity of $f\left(t^{1 / v}\right)$ it follows that the function $t^{1-v} f(t)$ is nondecreasing, thus we have 


$$
\begin{gathered}
\int_{0}^{+\infty}|T(f) y|^{(1-v)} f^{\prime}(|T(f) y|)|f(y)|^{v} d y \\
\leq \int_{0}^{+\infty} M^{(1-v)}(z(y))^{(1 / v)-1} f^{\prime}\left(M(z(y))^{1 / v}\right) z^{\prime}(y) d y \\
=\frac{v}{M^{v}} \int_{0}^{+\infty} f^{\prime}\left(M(z(y))^{1 / v}\right) \cdot d\left(M(z(y))^{1 / v}\right) \\
=\frac{v}{M^{v}} f(M(z(+\infty)))^{1 / v} \\
=\frac{v}{M^{v}} f\left(M\left(\int_{0}^{+\infty}|f(y)|^{v} d y\right)^{1 / v}\right) .
\end{gathered}
$$

This completes the proof.

\section{Acknowledgements}

The research of Chang-Jian Zhao was supported by the National Natural Science Foundation of China (10971205), and the research of Wing-Sum Cheung was partially supported by a HKU URC grant.

\section{Author details}

${ }^{1}$ Department of Mathematics, China Jiliang University, Hangzhou 310018, China ${ }^{2}$ Department of Mathematics, The University of Hong Kong, Pokfulam Road, Hong Kong

\section{Authors' contributions}

C-JZ and W-SC jointly contributed to the main results Theorems 2.1 and 2.4. All authors read and approved the final manuscript.

\section{Competing interests}

The authors declare that they have no competing interests.

Received: 8 February 2012 Accepted: 30 May 2012 Published: 30 May 2012

\section{References}

1. Opial, Z: Sur une inégalité. Ann Polon Math. 8, 29-32 (1960)

2. Willett, D: The existence-uniqueness theorem for an $n$th order linear ordinary differential equation. Am Math Monthly. 75, 174-178 (1968). doi:10.2307/2315901

3. Hua, LK: On an inequality of Opial. Sci China. 14, 789-790 (1965)

4. Godunova, EK: Integral'nye neravenstva s proizvodnysi i proizvol'nymi vypuklymi funkcijami. Uc Zap Mosk Gos Ped In-ta im Lenina. 460, 58-65 (1972)

5. Rozanova, Gl: On an inequality of Maroni (Russian). Math Zametki. 2, 221-224 (1967)

6. Das, KM: An inequality similar to Opial's inequality. Proc Am Math Soc. 22, 258-261 (1969)

7. Agarwal, RP, Thandapani, E: On some new integrodifferential inequalities. Anal sti Univ "Al I Cuza" din lasi. 28, 123-126 (1982)

8. Yang, GS: A note on inequality similar to Opial inequality. Tamkang J Math. 18, 101-104 (1987)

9. Agarwal, RP, Lakshmikantham, V: Uniqueness and Nonuniqueness Criteria for Ordinary Differential Equations. World Scientific, Singapore (1993)

10. Bainov, D, Simeonov, P: Integral Inequalities and Applications. Kluwer Academic Publishers, Dordrecht (1992)

11. Li, JD: Opial-type integral inequalities involving several higher order derivatives. J Math Anal Appl. 167, $98-100$ (1992). doi:10.1016/0022-247X(92)90238-9

12. Cheung, WS: On Opial-type inequalities in two variables. Aequationes Math. 38, 236-244 (1989). doi:10.1007/ BF01840008

13. Cheung, WS: Some generalized Opial-type inequalities. J Math Anal Appl. 162, 317-321 (1991). doi:10.1016/0022-247X (91)90152-P

14. Zhao, CJ, Cheung, WS: Sharp integral inequalities involving high-order partial derivatives. J Inequal Appl 2008, 1-10 (2008). Article ID 571417

15. Agarwal, RP, Pang, PYH: Sharp opial-type inequalities in two variables. Appl Anal. 56(3), 227-242 (1996)

16. Agarwal, RP, Pang, PYH: Opial Inequalities with Applications in Differential and Difference Equations. Kluwer Academic Publishers, Dordrecht (1995)

17. Mitrinović, DS, Pečarić, JE: Generalizations of two inequalities of Godunova and Levin. Polish Acad Sci Math. 36 , 645-648 (1988)

18. Godunova, EK, Levin, VI: O neikotoryh integralnyh nerabenstvah, soderzascih proizvodnye (Russian). Izv vuzov Matem. 91, 20-24 (1969)

doi:10.1186/1029-242X-2012-123

Cite this article as: Zhao and Cheung: On Opial's type inequalities for an integral operator with homogeneous

kernel. Journal of Inequalities and Applications 2012 2012:123. 